others starved or had to be killed later. Unfortunately, the obvious lessons from Allison had not been applied in New Orleans in time for Katrina.

Relatively simple precautions can often prepare laboratories to deal with natural disasters, especially in regions where the risk is known to be high. In earthquake-prone San Francisco, researchers typically know how well their buildings are constructed to withstand a quake, and sometimes practise procedures for evacuation in such an event. In New Orleans, researchers had lived with the threat of flooding for years. Yet the threat was perceived as indeterminate - everything, it seemed, would be fine, except in the event of a levee breaking. Of course, the levee broke.

Subsequent events should remind scientists in regions where such risks exist to revisit their own laboratories' emergency preparations. Researchers who work with animals should prepare a tagging system to help them identify the animals most crucial to their work. In the case of power outages, rescuers can identify those animals through their brightly coloured tags and know to take them out first.

Those with crucial cell lines in need of refrigeration should make sure that back-up systems are in place to keep the samples cold. Dry-ice can serve to keep precious samples refrigerated, even if the power is out for several days.

For most organizations, maintaining communications will be the most critical aspect of disaster recovery. Laboratories should ensure they have up-to-date telephone numbers for all members of the lab, and a system in place for who should contact whom in an emergency. E-mail systems should be backed up on remote servers, so they can be kept running throughout. These steps assume, of course, that some infrastructure will continue to function within a nearby community, where evacuees can regroup.

Such preparations rarely take priority until disaster strikes. But every researcher, from lab head to summer student, should look at what surrounds them, apply some common sense, and acquaint themselves with the basics of disaster recovery for their laboratory.

\section{Foo's paradise}

\section{In praise of chat.}

I's not uncommon to hear despairing complaints about some highpowered meeting that it was 'nothing more than a talking shop'. If one is going to all the trouble of gathering these people, the accusation suggests, it should deliver something.

That's a fair complaint when hard-edged achievement is the avowed intention. But maybe too little credence is given to gatherings that are expressly intended to foster conversation, organized in the enlightened hope that people will be stimulated and that unanticipated developments will follow. The duty of the organizers, then, is simply to maximize the chances of positive encounters.

Some years ago, the publisher Tim O'Reilly and his colleagues conceived the idea of just such a talkfest. O'Reilly is an influential enthusiast of participative web activities such as wikis and blogs. And in the same spirit, the programme of such meetings is developed on the spot by the 100-odd participants, who arrive at some enjoyable location and camp together for three days. The initial idea was to invite 'friends of O'Reilly', and thus was the first 'Foo camp' conceived. True to form, no grand manifestos or initiatives have emerged, but there has been plenty of stimulation and, no doubt, some upward blips in the revenues of manufacturers of alcoholic beverages.

Given the interest of Nature and its publishers in participatory publishing - see, for example, the strings of comments on some of the news stories of news@nature.com and our trial of open peer review (http://blogs.nature.com/nature/peerreview/trial/) — it was no surprise that we should fraternize with O'Reilly and conceive the idea of a science Foo. And it was gratifying that Google thought the idea sufficiently fun to be worth hosting such a get-together. And so it was that 200 people - scientists, mainly, infused with technologists and writers - turned up at the 'Googleplex' in Mountain View, California, earlier this month, for a long weekend of chat.

Invitees, who ranged across disciplines, age and nationality, were not told who else was coming. They were simply invited to get themselves there. Formal presentations were not encouraged. And the key to the dynamic was the programme: a wall chart with an empty matrix of one-hour sessions in a number of variously sized rooms stretching across two-and-a-half days, each session to be specified by any individual attendee as the meeting progressed. (It was fun to see who rated their session as worthy of 150 people's attention, and who offered their topic to a mere eight.)

After an introductory session, the participants developed a programme of titles such as 'how to radicalize scientists', 'open peer review and science wikis', 'the future of human evolution', 'text mining, 'educational robotics', 'global health', 'the semantic web and the life sciences', and 'citizen scientists' (which features in this week's Nature podcast).

Inevitably such meetings will pick up on common concerns of the moment - such as the relationship between science and politics, how scientists should deal with fallacious media coverage, the balance between open and proprietary approaches to anything and everything. But there were plenty of uncommon ideas too, such as putting an atmospheric sensor on every mobile phone, and analysing the 'parameter space' of sciences and technologies in order to map and anticipate future advances.

The exercise could be portrayed by
"Many attendees commented on the stimulation of getting feedback on their ideas from an unusual mix of expertise." cost-conscious administrators as a colossal act of self-indulgence. But, for example, an entrepreneur who wants to design a \$20 float for an oceanography experiment got some ideas about how to move his project forward, and an advocate of public participation in clinical trials was given feedback on her plans to use home DNA kits to boost involvement in a cancer trial. Many attendees commented on the stimulation of getting feedback on their ideas from an unusual mix of expertise.

But above all, it was the mode of spontaneous organization that gave the meeting a drive that is unusual and worth promoting. If this is what a talking-shop can be like, let's have more of them. 